\title{
The Impact of Age and Duration of Cochlear Implant in a Congenital Deaf Population: An ERP Study
}

\author{
Sara Ghiselli ${ }^{*}$, Flavia Gheller ${ }^{1}$, Patrizia Trevisi ${ }^{1}$, Patrizia Rampazzoㄹ, Mario Ermani², \\ Alessandro Martini ${ }^{1}$ \\ ${ }^{1}$ ENT Clinic, Department of Neuroscience, Padova University Hospital, Padova, Italy \\ ${ }^{2}$ Neurological Clinic, Department of Neuroscience, Padova University Hospital, Padova, Italy \\ Email: ${ }^{*}$ saraghiselli80@gmail.com
}

Received 12 April 2016; accepted 26 June 2016; published 30 June 2016

Copyright (C) 2016 by authors and Scientific Research Publishing Inc.

This work is licensed under the Creative Commons Attribution International License (CC BY). http://creativecommons.org/licenses/by/4.0/

(c) (i) Open Access

\begin{abstract}
Objective: It is well known that patients with Cochlear Implant (CI) have a large inter-individual variability in linguistic and auditory performances. This can be related to individual auditory processing abilities and integrity of auditory system from auditory nerve to cerebral cortex. P300 can be used for the evaluation of central auditory functions in people with hearing loss and CI. No studies considered the P300 in the population of prelingually deafened adults that underwent $\mathrm{CI}$ in old age. The aim of this study is to assess Event Related Potential (ERP) in patients with congenital profound hearing loss with early or late implantation and evaluate these results respect to an age-matched normal hearing group. Methods: ERPs (N100, N200 and P300) and auditory benefit testing (pure tone average and speech audiometric test) and auditory perception testing (Categories of Auditory Performance-CAP) were evaluated in all subjects with their device. Results: All mean latencies (N100, N200 and P300) were found greater in patients group compared to control group. When analyzing all measures in patient group, we did not find any significant differences according to age of implant while significant difference $(p>0.05)$ in $N 100$ amplitude $(p=0.045)$ and P300 latency $(p=0.035)$ were found according to time of $\mathrm{CI}$ use. A linear correlation between N200 and P300 latency in control and patients groups was found. Conclusion: In summary, ERPs analysis in the evaluation of CI showed a great importance of long use of the device in addiction to an early time of implant.
\end{abstract}

\section{Keywords}

Hearing Loss, Cochlear Implant, Event Related Potential, ERPs, P300

\footnotetext{
"Corresponding author.
}

How to cite this paper: Ghiselli, S., Gheller, F., Trevisi, P., Rampazzo, P., Ermani, M. and Martini, A. (2016) The Impact of Age and Duration of Cochlear Implant in a Congenital Deaf Population: An ERP Study. J. Biomedical Science and Engineering, 9, 384-392. http://dx.doi.org/10.4236/jbise.2016.98033 


\section{Introduction}

Cochlear Implant (CI) is a medical device for introducing or restoring hearing in deaf people with severe to profound hearing loss that get not sufficient advantages from conventional hearing aids [1].

In 2010 about 300,000 CI users were estimated to be in the world and 80,000 of them were deaf children [2]. In Italy, about 6000 - 7000 patients have been implanted till now and every year 700 cochlear implants on average are carried out [3].

CI has two main parts: external and internal.

The external removable part is composed by a microphone, a small battery for processing the signal and an induction coil for transmitting refined signals through the skin to the implant [4].

The internal component is surgically positioned in the temporal bone and it is connected to an electrode array located in the cochlea. The array stimulates directly the auditory nerve fibers by passing damaged inner ear (hair cells).

The internal component works only when the external part is active, without a direct connection.

It is well known that patients with CI have a large inter-individual variability in linguistic and auditory performances. This can be related to individual auditory processing abilities and integrity of auditory system from auditory nerve to cerebral cortex. Indeed, performances are correlated to age of onset and time of hearing loss, etiology and number of cells in spiral ganglion [5] [6].

P300 potential (an Event Related Potential, ERP) shows the cortical electrophysiological activity involved in attention, memory, discrimination, integration and decision making skills [7] [8]. Auditory P300 may reflect the conscious process of acoustic differences present in speech signal [9].

P300 has been widely used for the evaluation of central auditory functions in people with hearing loss [8] [10] [11]. These studies report an evaluation of latency and amplitude of different ERPs (N1, P2, N2 and P300 for Polen et al.; N1, N2, P300 and mismatch negativity for Oates et al. and only P300 potential for Reis et al.) in relation to the degree of the hearing impairment or to the complexity of the recognition tasks. However, none of them mentioned the correlation between latencies.

Furthermore, many studies used P300 in evaluating deaf people with cochlear implant with respect to time of use of the device, performances and stimulus administered.

Generally, implanted post verbal adult patients showed longer latencies compared to hearing patients with the same age [12]-[15].

In relation to auditory outcome, different studies report that implanted patients with good performances have P300 potential (latency and amplitude) similar to hearing people with the same age. Instead, implanted subjects with poor performance have absent or modified responses [16] [17].

Time of use of the device is also very important. Adult patients with post-verbal hearing loss and CI show a reduced latency and an increased amplitude of the P300 over time [13].

Environmental noise, stimulation strategies, type and model of the cochlear implant are other factors which may affect the latency and amplitude of P300 potential [17] [18].

Kileny et al. (1997) and Henkin et al. (2008) studied a population of respectively 14 and 10 prelingually deaf children [19] [20]. Kileny et al. correlated the N1, P2, N2 and P3 latencies in relation to type of task and speech recognition, without a control group [19]. No studies considered the P300 in the population of prelingually deaf adults which underwent to cochlear implant in old age.

The aim of this study is to assess the ERPs (N100, N200 and P300) in patients with congenital profound hearing loss with early or late implantation and evaluate these results respect to an age-matched normal hearing group.

\section{Materials and Methods}

\subsection{Patients}

We enrolled 9 subjects in the control group ( 2 males and 7 females) and 15 subjects in the study group ( 9 males and 6 females) matched for age (control group mean age $27.7 \pm 15.5$; patient group mean age $25.4 \pm 16$ ). The age difference was not statistically significant $(\mathrm{p}=0.73)$.

All subjects were enrolled from ENT Clinic of University Hospital of Padua from November 2014 to January 2016. The inclusion criteria for the study group were: 1 ) congenital severe to profound bilateral sensorineural hearing loss (diagnosis before 18 months of life); 2) use of CI; 3) absence of associated disabilities or associated 
diseases; d) patient age: older than 6 years.

Data were examined in agreement with the Italian privacy and sensible data laws (D. Lgs 196/03) and to the ENT Clinic of University Hospital of Padua inside rules.

Patients were divided into two groups according to the age at the time of implantation: EARLY IMPLANTED group (EIG) for subjects implanted before 3 years, and LATE IMPLANTED group (LIG) for patients implanted after 15 years; 7 subjects were enrolled in EIG and 8 subjects in LIG.

At the time of this study, the mean age was $12.39 \pm 2.9$ (range: $7.7-16.5$ ) for EIG and $36.7 \pm 13.7$ (range: 17.9 - 57.7) for LIG.

Furthermore we dichotomized the patient group in a subgroup with a short period of IC use ( $<1$ year; 3 patients, SPU group) and a subgroup with a larger period ( $\geq 1$ year; 12 patients, LPU group).

Patient group characteristics are summarized in Table 1.

Table 2 shows audiological and perception skills of the subject in patient group.

Table 1. Patient group clinical characteristics.

\begin{tabular}{ccccccc}
\hline Patient & Gender & Age & Etiology & CI Age & Side & Brand \\
\hline $\mathbf{1}$ & F & 16.51 & Unknown & 1.51 & C & Cochlear \\
$\mathbf{2}$ & M & 7.75 & CX26 & 2.27 & L & Cochlear \\
$\mathbf{3}$ & F & 14.82 & CX26 & 1.55 & R & AB \\
$\mathbf{4}$ & F & 13.29 & CX26 & 2.6 & R & AB \\
$\mathbf{5}$ & M & 11.30 & Unknown & 2.7 & R & Cochlear \\
$\mathbf{6}$ & M & 39.20 & Rubella & 38.85 & $\mathrm{R}$ & AB \\
$\mathbf{7}$ & M & 41.99 & Rubella & 39.86 & $\mathrm{R}$ & $\mathrm{AB}$ \\
$\mathbf{8}$ & $\mathrm{M}$ & 12.41 & CX26 & 1.63 & $\mathrm{R}$ & $\mathrm{AB}$ \\
$\mathbf{9}$ & $\mathrm{F}$ & 42.38 & Unknown & 41.31 & $\mathrm{~L}$ & $\mathrm{AB}$ \\
$\mathbf{1 0}$ & $\mathrm{M}$ & 10.69 & Unknown & 1.18 & $\mathrm{R}$ & $\mathrm{AB}$ \\
$\mathbf{1 1}$ & $\mathrm{M}$ & 47.32 & Unknown & 42.96 & $\mathrm{BIL}$ & $\mathrm{AB}$ \\
$\mathbf{1 2}$ & $\mathrm{F}$ & 21.50 & CX26 & 16.77 & $\mathrm{R}$ & Cochlear \\
$\mathbf{1 3}$ & $\mathrm{M}$ & 17.92 & CX26 & 17.21 & $\mathrm{~L}$ & $\mathrm{AB}$ \\
$\mathbf{1 4}$ & $\mathrm{F}$ & 25.83 & Unknown & 22.52 & $\mathrm{~L}$ & Cochlear \\
$\mathbf{1 5}$ & $\mathrm{M}$ & 57.69 & Unknown & 57.36 & $\mathrm{~L}$ & $\mathrm{AB}$ \\
\hline
\end{tabular}

Table 2. Audiological and perceptive skills in patient group.

\begin{tabular}{|c|c|c|c|c|}
\hline Patient & CI PTA & SDT & SRT & CAP \\
\hline 1 & 21.67 & 10 & 30 & 7 \\
\hline 2 & 25 & 10 & 25 & 6 \\
\hline 3 & 41.67 & 30 & 45 & 7 \\
\hline 4 & 35 & 20 & 30 & 7 \\
\hline 5 & 30 & 20 & 35 & 7 \\
\hline 6 & 46.67 & 30 & 45 & 7 \\
\hline 7 & 35 & 30 & 45 & 5 \\
\hline 8 & 30 & 20 & 35 & 7 \\
\hline 9 & 30 & 30 & 40 & 6 \\
\hline 10 & 33.33 & 20 & 35 & 7 \\
\hline 11 & 26.67 & 35 & 50 & 5 \\
\hline 12 & 30 & 30 & 50 & 6 \\
\hline 13 & 48.33 & 40 & 60 & 5 \\
\hline 14 & 23.33 & 20 & 30 & 7 \\
\hline 15 & 60 & 60 & n.r. & 4 \\
\hline
\end{tabular}

PTA = Pure Tone Average; SDT = Speech Detection Threshold; SRT = Speech Recognition Threshold; CAP = Category of Auditory Performance score; n.r. = no recognition. 
Before the study, all subjects (or guardian) completed informed consent in agreement with Italian privacy and sensible data laws (D. Lgs 196/03).

All subjects underwent to auditory benefit testing, auditory perception testing and P300 recording in one day of examination:

\section{- Auditory benefit testing}

The auditory benefit of the CI was evaluated measuring the threshold to narrow-band stimuli in free field (Pure Tone Average-PTA) that is expressed in decibels hearing level (dB HL) and that corresponds to the average of the air-tonal threshold at the frequencies 500, 1000, $2000 \mathrm{~Hz}$. The subjects also underwent speech audiometry test that was performed by means of the speech audiometry in free field, disyllabic words for adults test [21], allowing us to verify the Speech Detection Threshold (SDT) and the Speech Recognition Threshold (SRT), using the device. SDT correspond to the lowest hearing level (expressed in decibels) at which the patient is able to distinguish the spoken word $50 \%$ of the time. SRT correspond to the lowest hearing level at which the patient is able to correctly repeat $50 \%$ of a list of words, using his/her implant.

The patient performances were classify by an evaluation questionnaire: Categories of Auditory Performance (CAP) [22]. CAP is composed by eight levels of skills that increase in difficulty, from no awareness of environmental sounds (category 0 ) to the telephone use with a known speaker (category 7), using their device.

- P300 recording

EEG recordings were carried out from 19 electrodes positioned according to the International 10 - 20 System with linked ear reference. Sampling rate was $1024 \mathrm{~Hz}$. Accordingly with literature and clinical practice, which identify in $\mathrm{Cz}$ the better evoked response, we performed all analysis considering Cz. A time window of $700 \mathrm{~ms}$ was considered (70 ms pre and $630 \mathrm{~ms}$ post stimulus).

The active oddball paradigm was used and consisted of a sequence of 280 standard and 40 target stimuli, randomly presented to the subjects. Stimuli were audio tone of different frequencies (1000 $\mathrm{Hz}$ for standard and $2000 \mathrm{~Hz}$ for the target, duration $100 \mathrm{~ms}$ for both; ISI $=1020-1100$; intensity $=90 \mathrm{~dB}$ ). Subjects were asked to take account of the number of target stimuli administered.

\subsection{Statistical Analysis}

For normally distributed variables, the $\mathrm{T}$ test for independent groups was used, while for no normally distributed variables the no parametric Mann Whitney $U$ test was performed. Linear correlations between latencies values were tested using the linear regression model. Responses after stimulus (630 ms) were collapsed in 63 bins, each resulting from the mean values of $10 \mathrm{~ms}$. ANOVA for repeated measures was applied to these data, and the within (63 bins), between (control or patients group) and interaction effects were evaluated. Significance level was set at $\mathrm{p}<0.05$. All analyses were performed using the Statistica 12.0 software package.

\section{Results}

Figure 1 and Figure 2 depicted the P300 raw data of control and patient group respectively, in Cz.

Anova for repeated measures showed a very high significant difference between P300 Grand Average in control and patient group (Figure 3; $\mathrm{p}<0.00001$ ).

When analyzing N100, N200 and P300 latency, significant differences were found for all measures between group, being mean latency greater in patients group (117.5 $\pm 14.7 \mathrm{~ms}$ vs. $88.2 \pm 13 \mathrm{~ms}, \mathrm{p}=0.0001$ for N100; $219.13 \pm 24.3 \mathrm{~ms}$ vs. $196.7 \pm 19.3 \mathrm{~ms}, \mathrm{p}=0.02$ for $\mathrm{N} 200$ and $349.5 \pm 50.2 \mathrm{~ms}$ vs. $293.5 \pm 27 \mathrm{~ms}, \mathrm{p}=0.005$ for P300). No significant differences were found for amplitudes.

Anova for repeated measures did not found any significant differences when comparing EIG and LIG groups (p > 0.05) (Figure 4).

Considering the SPU and LPU group a significant difference in N100 amplitude (2.5 $\pm 2.8 \mu \mathrm{V}$ vs. $7 \pm 4 \mu \mathrm{V}$ respectively, one sided Mann Whitney U test: $\mathrm{p}=0.045)$, and P300 latency (404 $\pm 47 \mathrm{~ms}$ vs. $336 \pm 42.4$ ms respectively; one sided Mann Whitney U test: $\mathrm{p}=0.035$ ).

When considering the linear correlation between N200 and P300 latency in control and patients groups a nearly perfect parallel regression line was found, as depicted in Figure 5.

Interestingly, two out of the three outliers patients belonged to SPU group and the third had a relative short period of CI use. Furthermore, the P300-N200 latency difference in SPU group was significant greater than in LPU one (182 \pm 60 ms vs. $117.15 \pm 35.4$ ms; one sided Mann Whitney U test: $\mathrm{p}=0.045$ ). 


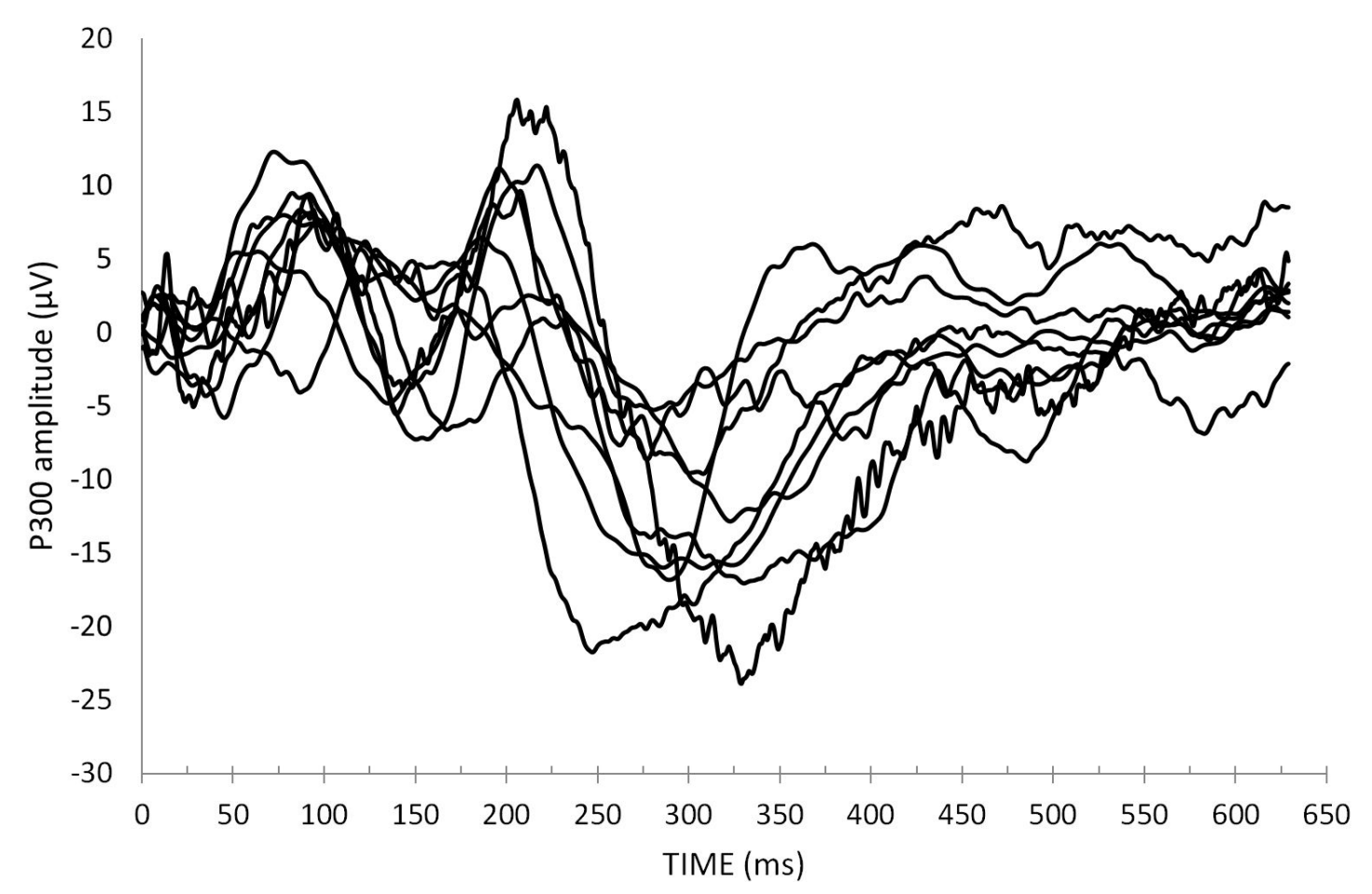

Figure 1. Control group N100, N200 and P300 in Cz channel.

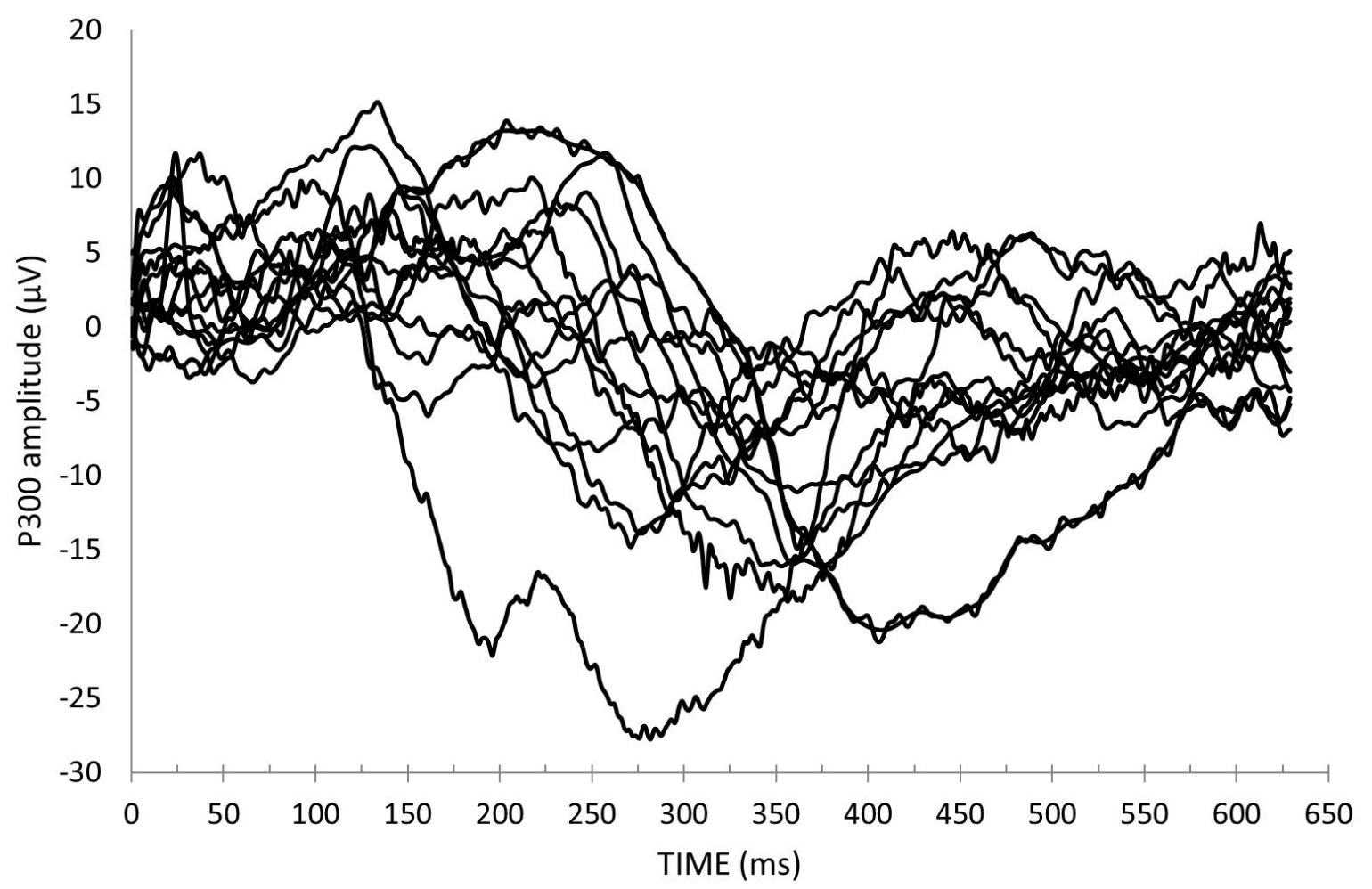

Figure 2. Patient group N100, N200 and P300 in Cz channel.

Finally, no significant correlations were found between CI PTA, SDT, SRT and all ERP measures (N100, N200 and P300 latencies and amplitudes). 


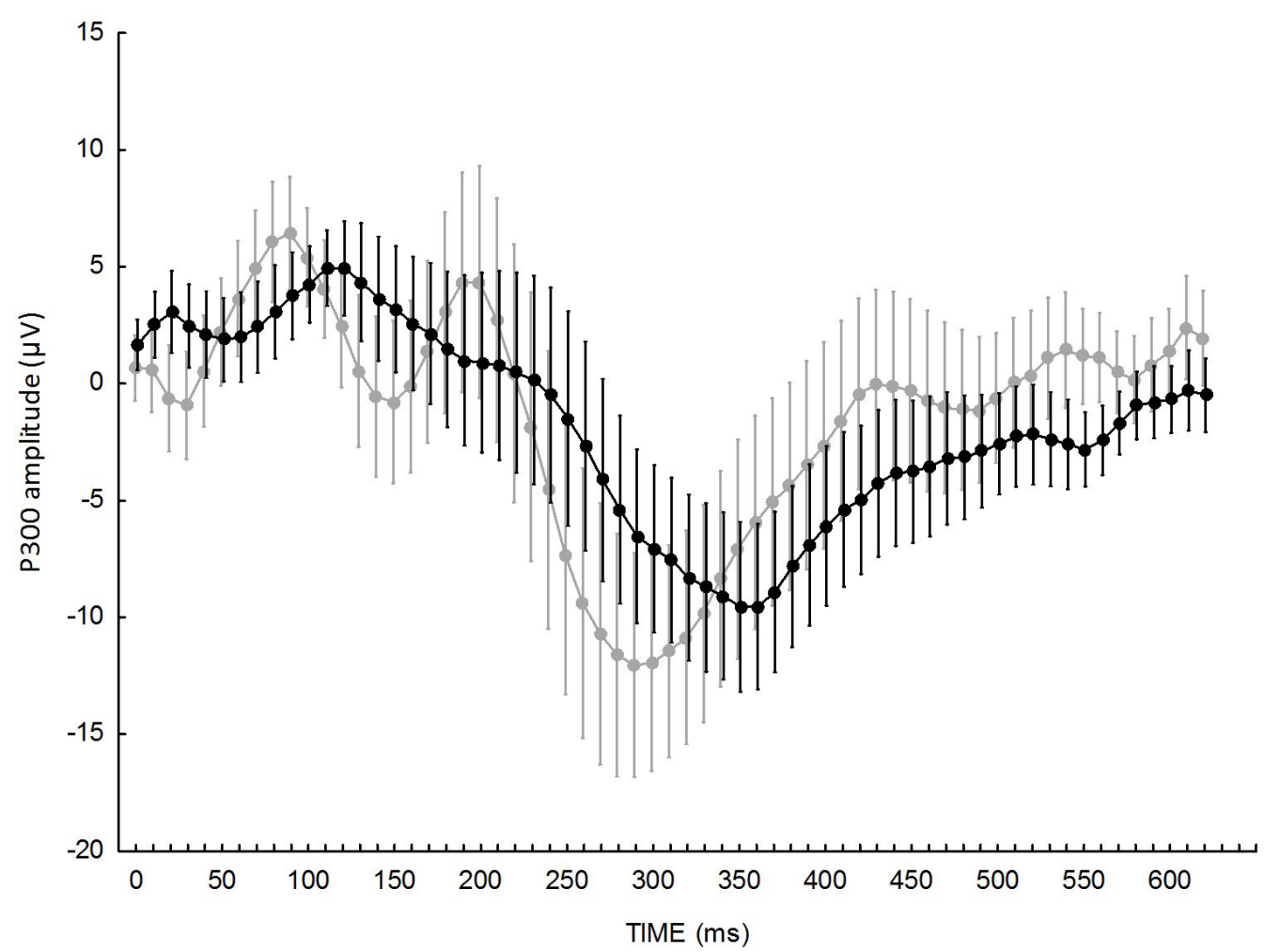

Figure 3. P300 Grand Average in control (in grey) and patient (in black) group.

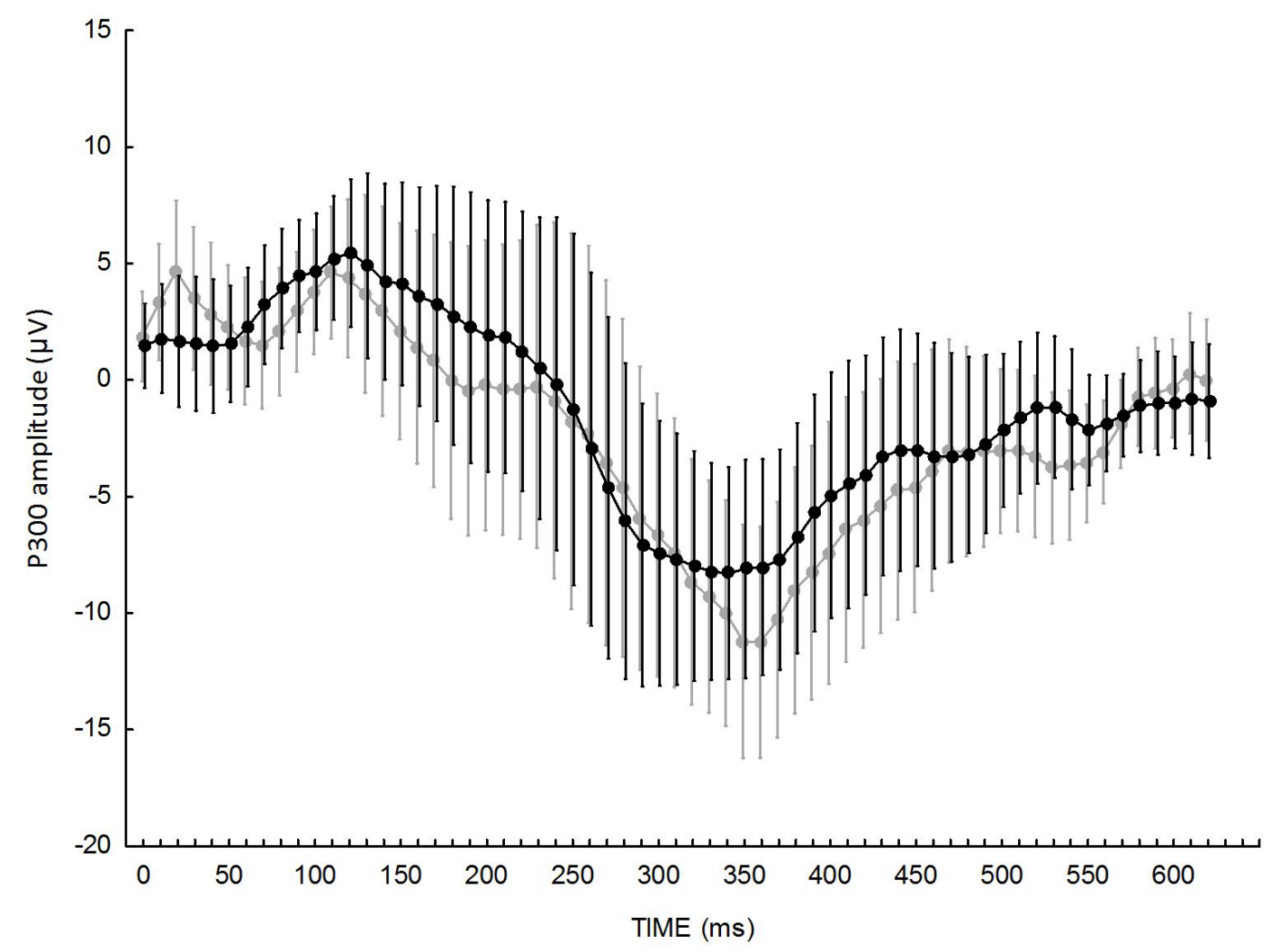

Figure 4. P300 Grand Average in EIG (in grey) and LIG (in black) group. 


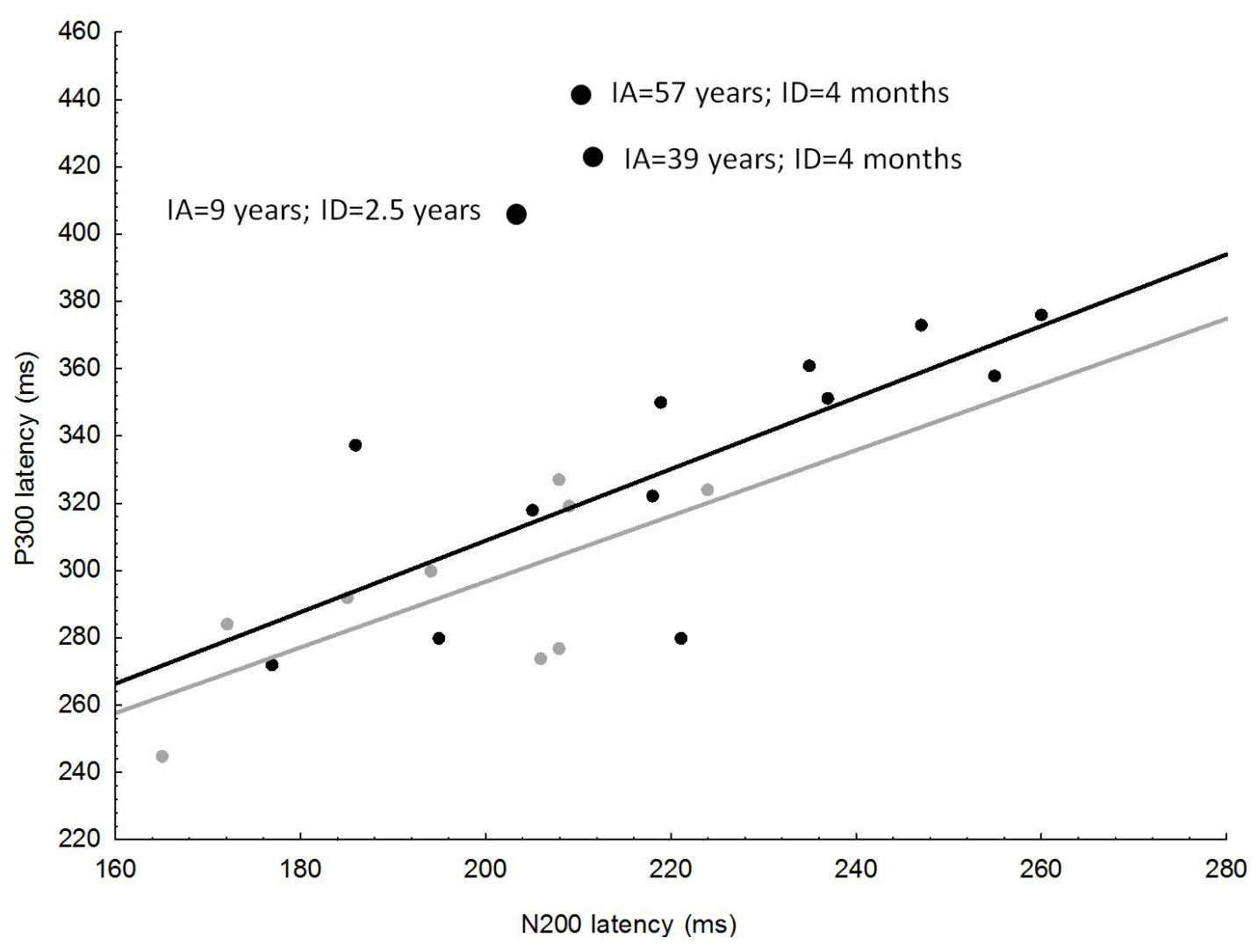

Figure 5. Scatterplot and linear correlation between P300 and N200 latencies in patients (in black) and control (in grey) group. ID = Implant Duration; IA = Implant Age. No significant difference between the two correlation coefficients $(\mathrm{p}=0.78)$

\section{Discussion}

In our study, as previously reported in literature, a significant longer N100, N200 and P300 latencies in patients group were found when compared to control group. Interestingly, no differences were found between EIG and LIG groups, suggesting that the old age of surgery didn't affect the outcome.

Time interval between N100 and N200 (103 \pm 24 ms vs. $108.5 \pm 14.2$ ms, respectively for patients and control group) was not significantly ( $\mathrm{p}=0.55)$ same as for the time interval between N100 and P300 (222.3 $\pm 41.3 \mathrm{~ms}$ vs. $205.3 \pm 25.8 \mathrm{~ms}$ respectively for patients and control group, $\mathrm{p}=0.28$ ). These results, considering that P300 latency was found to be significant longer in the patient group, can be explained assuming that the increasing latency of N100 is the most important feature, introducing a time delay in subsequent N200 and P300 latencies. In fact, when mean P300 latency was calculated in the patients group without the three outliers reported in results section, its value was $331.5 \pm 37.1 \mathrm{~ms}$; this differs from the mean value of control group (293.5 $\pm 27.1 \mathrm{~ms})$ of $38 \mathrm{~ms}$, that is very close to the difference in N100 value latencies between control and patients group (30 ms). Interestingly two of the three outliers belonged to late implanted group with a very short time of implant use while the other one belonged to the early implanted group with a relative short time of implant use. Moreover, the linear regression between N200 and P300 latencies, calculated excluding these outliers, is perfectly parallel in control and patients group.

Considering all these findings together, we can hypothesize that, when a "congruent" time of implant use is reached, the P300 pattern of patients is the same of the control cases, with a delay due to the N100 delay probably generated by the device.

In spite of the small sample size, this study had a power of more than $90 \%$ in detecting significant differences in N100 latencies and more than 85\% in detecting significant differences in P300 latencies. Conversely, the power was very low when comparing results between LPU and SPU group.

Our purpose is to increase the number of SPU patients, with the intent to define when a time of implant use 
can be "congruent".

Further prospective studies are required to evaluate the localization of the ERPs cortical sources in implanted and control group.

In summary, ERPs analysis in the evaluation of CI showed a great importance of long use of the device in addiction to an early time of implant.

\section{Conflict of Interest and Funding}

The authors have no conflicts of interest to disclose

Prof. Alessandro Martini and Prof. Mario Ermani contributed equally to the preparation of this paper and should be considered jointly as last co-authors.

\section{References}

[1] Gates, G.A. and Miyamoto, R.T. (2003) Cochlear Implants. The New England Journal of Medicine, 349, 421-423. http://dx.doi.org/10.1056/NEJMp038107

[2] Kral, A. and O’Donoghue, G.M. (2010) Profound Deafness in Childhood. The New England Journal of Medicine, 363, 1438-1450. http://dx.doi.org/10.1056/NEJMra0911225

[3] Martini, A., Bovo, R., Trevisi, P., Forli, F. and Berrettini, S. (2013) Cochlear Implant in Children: Rational, Indications and Cost/Efficacy. Minerva Pediatrica, 65, 325-339

[4] Ramsden, R. and Graham, J. (1995) Cochlear Implantation. BMJ, 311, 1588. http://dx.doi.org/10.1136/bmj.311.7020.1588

[5] Ponton, C.W., Don, M., Eggermont, J.J., Waring, M.D., Kwong, B. and Masuda, A. (1996) Auditory System Plasticity in Children after Long Periods of Complete Deafness. NeuroReport, 8, 61-65. http://dx.doi.org/10.1097/00001756-199612200-00013

[6] Sharma, A., Dorman, M.F. and Spahr, A.J. (2002) A Sensitive Period for the Development of the Central Auditory System in Children with Cochlear Implants: Implication for Age of Implantation. Ear and Hearing, 23, 532-539. http://dx.doi.org/10.1097/00003446-200212000-00004

[7] Polich, J. and Herbst, K.L. (2000) P300 as a Clinical Assay: Rationale, Evaluation, and Findings. International Journal of Psychophysiology, 38, 3-19. http://dx.doi.org/10.1016/S0167-8760(00)00127-6

[8] Reis, A.C.M., Frizzo, A.C., Isaac, M.de.L., Garcia, C.F., Funayama, C.A. and Iório, M.C. (2015) P300 in Individuals with Sensorineural Hearing Loss. Brazilian Journal of Otorhinolaryngology, 81, 126-132. http://dx.doi.org/10.1016/j.bjorl.2014.10.001

[9] Martin, B.A., Tremblay, K.L. and Korczak, P. (2008) Speech Evoked Potentials: From the Laboratory to the Clinic. Ear and Hearing, 29, 285-313. http://dx.doi.org/10.1097/AUD.0b013e3181662c0e

[10] Polen, S.B. (1984) Auditory Event Related Potentials. Seminars in Hearing, 5, 127-141. http://dx.doi.org/10.1055/s-0028-1095227

[11] Oates, P.A., Kurtzberg, D. and Stapells, D.R. (2002) Effects of Sensorineural Hearing Loss on Cortical Event-Related Potential and Behavioral Measures of Speech-Sound Processing. Ear and Hearing, 23, 399-415. http://dx.doi.org/10.1097/00003446-200210000-00002

[12] Oviatt, D.L. and Kileny, P.R. (1991) Auditory Event-Related Potentials Elicited from Cochlear Implant Recipients and Hearing Subjects. American Journal of Audiology, 1, 48-55. http://dx.doi.org/10.1044/1059-0889.0101.48

[13] Kelly, A.S., Purdy, S.C. and Thorne, P.R. (2005) Electrophysiological and Speech Perception Measures of Auditory Processing in Experienced Adult Cochlear Implant Users. Clinical Neurophysiology, 116, 1235-1246. http://dx.doi.org/10.1016/j.clinph.2005.02.011

[14] Henkin, Y., Tetin-Schneider, S., Hildesheimer, M. and Kishon-Rabin, L. (2009) Cortical Neural Activity Underlying Speech Perception in Postlingual Adult Cochlear Implant Recipients. Audiology and Neurotology, 14, 39-53. http://dx.doi.org/10.1159/000153434

[15] Obuchi, C., Harashima, T. and Shiroma, M. (2012) Auditory Evoked Potentials under Active and Passive Hearing Conditions in Adult Cochlear Implant Users. Clinical and Experimental Otorhinolaryngology, 5, S6-S9. http://dx.doi.org/10.3342/ceo.2012.5.S1.S6

[16] Micco, A.G., Kraus, N., Koch, D.B., McGee, T.J., Carrell, T.D., Sharma, A., Nicol, T. and Wiet, RJ. (1995) Speech-Evoked Cognitive P300 Potentials in Cochlear Implant Recipients. American Journal of Otolaryngology, 16, 514-520. 
[17] Soshi, T., Hisanaga, S., Kodama, N., Kanekama, Y., Samejima, Y., Yumoto, E. and Sekiyama, K. (2014) Event-Related Potentials for Better Speech Perception in Noise by Cochlear Implant Users. Hearing Research, 316, 110-121. http://dx.doi.org/10.1016/j.heares.2014.08.001

[18] Beynon, A.J. and Snik, A.F. (2004) Use of the Event-Related P300 Potential in Cochlear Implant Subjects for the Study of Strategy-Dependent Speech Processing. Internation Journal of Audiology, 143, S44-S47.

[19] Kileny, P.R., Boerst, A. and Zwolan, T. (1997) Cognitive Evoked Potentials to Speech and Tonal Stimuli in Children with Implants. Otolaryngology—Head and Neck Surgery, 117, 161-169. http://dx.doi.org/10.1016/S0194-5998(97)70169-4

[20] Henkin, Y., Kileny, P.R., Hildesheimer, M. and Kishon-Rabin, L. (2008) Phonetic Processing in Children with Cochlear Implants: An Auditory Event-Related Potentials Study. Ear and Hearing, 29, 239-249. http://dx.doi.org/10.1097/AUD.0b013e3181645304

[21] Cutugno, F., Prosser, S. and Turrini, M. (2000) Audiometria Vocale. GN. ReSound, Itay.

[22] Archbold, S. (1994) Monitoring Progress in Children at the preverbal Stage. Cochlear Implants for Young Children. Whurr, London.

\section{Submit or recommend next manuscript to SCIRP and we will provide best service for you:}

Accepting pre-submission inquiries through Email, Facebook, Linkedin, Twitter, etc A wide selection of journals (inclusive of 9 subjects, more than 200 journals)

Providing a 24-hour high-quality service

User-friendly online submission system

Fair and swift peer-review system

Efficient typesetting and proofreading procedure

Display of the result of downloads and visits, as well as the number of cited articles

Maximum dissemination of your research work

Submit your manuscript at: http://papersubmission.scirp.org/ 